\title{
KAJIAN PENERIMAAN PENGGUNA TERHADAP SISTEM CRM DI PERUSAHAAN X MENGGUNAKAN MODEL TAM
}

\author{
Muhammad Malik Hakim \\ Teknik Informatika, Universitas Muria Kudus \\ Email: malik.hakim@umk.ac.id
}

(Naskah masuk: 31 Desember 2017, diterima untuk diterbitkan: 2 Maret 2018

\begin{abstract}
Abstrak
Pelayanan kepada pelanggan adalah salah satu tujuan bisnis setiap perusahaan dalam upayanya memberikan kepuasan kepada para pelanggannya. Untuk mengintegrasikan seluruh kegiatan pelayanan kepada pelanggan dari semua divisi yang terkait baik langsung maupun tidak langsung, Perusahaan X sebagai perusahaan yang bergerak dalam bidang TI telah mengimplementasikan sistem CRM (Customer Relationship Management). Implementasi CRM tersebut bertujuan untuk mensinergikan kegiatan pelayanan kepada pelanggan agar tidak saling tumpang tindih dan dapat terkoordinasi dengan baik. Untuk mendukung kesuksesan dan keberlanjutan penggunaan sistem CRM, penelitian ini mengkaji penerimaan pengguna sistem CRM di antara semua karyawan dalam divisi terkait di dalam perusahaan yang berjumlah 141 orang, menggunakan Model TAM (Technology Acceptance Model) yang dimodifikasi, yaitu tanpa melibatkan variabel eksternal. Penelitian ini mengkaji penerimaan pengguna berdasarkan empat variabel penyusun Model TAM, yaitu Perceived Ease Of Use (PEOU), Perceived Usefulness (PU), Behavioral Intention (BI), dan Actual Use (AU). Studi membuktikan bahwa diperoleh pengaruh yang positif dan signifikan antara variabel - variabel penyusunnya, yaitu PEOU terhadap PU dan BI, PU terhadap BI, serta BI terhadap AU dengan nilai pengaruh masing - masing adalah 0,$43 ; 0,67 ; 0,58$; dan 0,77. Penelitian ini membuktikan bahwa penerimaan pengguna CRM sangat dipengaruhi oleh faktor manfaat, kemudahan, serta perilaku karyawan dalam menggunakannya.
\end{abstract}

Kata kunci: CRM, TAM Model, variabel TAM, model penerimaan pengguna, adopsi teknologi

\section{THE ANALYSIS ON ACCEPTANCE MODEL OF CRM SYSTEM IN COMPANYX USING TECHNOLOGY ACCEPTANCE MODEL}

\begin{abstract}
Every company strives to maintain its customer loyalty by delivering high satisfaction to its customers. To integrate all service activities to customers from all related divisions directly and indirectly, The Company X has implemented a CRM (Customer Relationship Management) system. Implementation of CRM aims to synergize service activities to customers among all division so that it can be well coordinated. To support the success and sustainability of CRM systems, this study analyzes the acceptance of CRM system among 141 related employees within the company using the modified TAM (Technology Acceptance Model) which excluding external factors from its constructing variables. This study investigates the user acceptance based on four variabels of TAM Model, namely Perceived Ease Of Use (PEOU), Perceived Usefulness (PU), Behavioral Intention (BI), and Actual Use (AU). Studies show that there are positive and significant influence between the studied construct variables; between PEOU on PU and BI, PU on BI, and BI on AU; with the influence value of 0,43; 0,67; 0,58; and 0,77 respectively. This indicates that user acceptance of CRM is strongly influenced by factors of benefit, convenience, and employee behavior in using the system.
\end{abstract}

Keywords: CRM, TAM Model, TAM variables, user acceptance model, technology adoption

\section{PENDAHULUAN}

Sistem informasi dalam suatu perusahaan pada umumnya diimplementasikan dengan investasi yang cukup besar. Perusahaan sangat memahami pentingnya implementasi sebuah sistem informasi untuk mengubah suatu proses bisnis agar menjadi lebih cepat, mudah diatur, terdokumentasikan dengan baik, serta dapat menghemat penggunaan sumber daya lain, terutama sumber daya terkait penggunaan dokumentasi dalam bentuk kertas. Oleh karena itu, implementasi sistem informasi harus diikuti dengan kajian untuk mengetahui tingkat 
penerimaan dari para pengguna sistem, untuk memastikan bahwa pengguna memiliki kemauan untuk terus menggunakan sistem tersebut, sehingga sistem dapat dioperasionalkan secara optimal. Perusahaan X sebagai sebuah perusahaan penyedia layanan dan solusi SI / TI bermaksud melakukan pengembangan SI dan TI nya untuk menyesuaikan dengan perkembangannya yang semakin besar. Langkah - langkah yang telah ditempuh antara lain melakukan audit terhadap sistem yang telah dimilikinya (Hakim, 2017a), kemudian melakukan perencanaan strategis terhadap sistem informasi yang dibutuhkan di masa datang (Hakim, 2017b), serta pada penelitian ini akan mengetahui sejauh mana tingkat penerimaan pengguna terhadap salah satu sistem informasi yang diimplementasikan.

Sistem yang menjadi objek kajian dalam penelitian ini adalah sistem CRM (Customer Relationship Management) yang merupakan salah satu sistem utama dalam proses bisnis memberikan pelayanan kepada pelanggan dalam bentuk penanganan dan pencatatan keluhan, perbaikan peralatan, dan program pemasaran. Seluruh karyawan di dalam divisi pemasaran dan penjualan yang bertanggungjawab terhadap pemasaran dan penjualan produk dan jasa kepada pelanggan, divisi pelayanan pelanggan (customer service/helpdesk) yang bertanggung jawab menerima saran dan keluhan pelanggan, serta divisi support and service yang bertanggungjawab memperbaiki kerusakan pada peralatan pelanggan memiliki kewajiban menggunakan sistem tersebut. Sistem CRM akan memproses segala bentuk urusan administrasi yang terkait dengan layanan pelanggan dan akan menghubungkannya dengan sistem lainnya seperti sistem persediaan suku cadang (inventory) dan sistem HR (human resource) dalam hal penugasan teknisi perbaikan jika diperlukan sesuai prosedur yang ada.

Kajian penerimaan pengguna terhadap implementasi CRM diperlukan untuk mengetahui sejauh mana tingkat penerimaan dari para penggunanya sehingga dapat diketahui tingkat kontinyuitas dan optimalisasi penggunaannya. Melalui kajian tersebut, akan diketahui faktor apa saja yang berpengaruh terhadap penggunaan CRM sehingga nantinya perusahaan dapat membuat kebijakan yang memungkinkan terbentuknya suasana yang mendukung pengguna agar penggunaan CRM dapat dilaksanakan secara konsisten dan kontinyu. Pada gilirannya, optimalisasi penggunaan CRM akan dapat mengoptimalkan investasi pada implementasi sistem informasi dalam perusahaan. Sehingga akan dapat diketahui secara jelas mengenai pengembangan sistem informasi tahap selanjutnya apakah akan menambah atau mengurangi fitur yang dimiliki suatu sistem, mengembangun sistem baru sebagai pelengkap atau bahkan sebagai pengganti dari sistem yang telah ada, atau menerapkan kebijakan dan standar tata kelola SI / TI secara khusus.

\section{KAJIAN PUSTAKA}

Model TAM (Technology Acceptance Model) merupakan bentuk pengembangan lebih lanjut dari Model TRA yang dikembangkan oleh Ajzen (Azhary dan Sari, 2008). Davis (1989) mengenalkan Model TAM untuk pertama kalinya, dimana selanjutnya mengalami beberapa modifikasi oleh para peneliti sesudahnya (Fatmawati, 2015). Pengembangan pada TAM lebih dititikberatkan pada sisi psikologis penggunanya, dimana Model TAM didasarkan pada pengalaman pengguna dalam menggunakan sistem atau teknologi yang diimplementasikan/diterapkan (Venkatesh dan Davis, 1996). Di luar variabel eksternal, pada dasarnya Model TAM dibentuk oleh dua variabel penentu, yaitu Perceived Usefulness (PU) dan Perceived Ease of Use (PEOU), dan ditambah dua variabel tidak bebas berupa Behavioral Intention (BI) dan Actual Sistem Use (AU) (Venkatesh dan Davis, 1996). Adapun detil Model TAM dapat dilihat pada Gambar 1 .

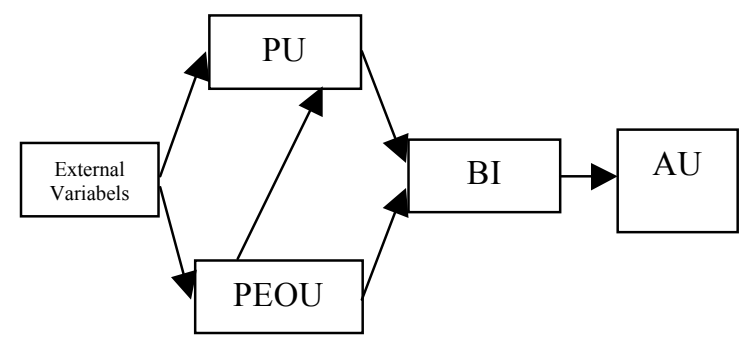

Gambar 1. Model TAM (Venkatesh dan Davis, 1996)

PU merupakan variabel yang merepresentasikan perasaan yang diperoleh dari pengalaman dan persepsi pengguna terhadap manfaat, yang dirasakan oleh pengguna sistem/teknologi tersebut. Variabel PU difokuskan pada pengalaman pengguna secara ekstrinsik, misalnya peningkatan kinerja, peningkatan efektivitas dan efisiensi dalam pekerjaan, produktivitas kerja, serta kecepatan penyelesaian pekerjaan. Sehingga, variabel PU adalah karakteristik ekstrinsik dari sebuah sistem atau teknologi yang dapat dirasakan manfaatnya oleh penggunanya.

Sedangkan PEOU dititikberatkan pada karakteristik intrinsik sistem/teknologi yaitu keberadaan fitur yang dapat dirasakan oleh penggunanya. Variabel PEOU lebih dititikberatkan pada kemudahan penggunaan yang dirasakan oleh penggunanya, seperti tingkat kemudahan penggunaan, fleksibilitas akses, kemudahan penguasaan, ketersediaan fitur bantuan, dan lain-lain yang fokus pada karakteristik intrinsik sebuah sistem. Sehingga, pengguna merasakan bahwa dengan sistem, usaha yang dilakukan oleh pengguna 
dalam menyelesaikan pekerjaannya akan semakin rendah.

BI merupakan variabel yang menunjukkan penerimaan pengguna terhadap sistem/teknologi yang digunakannya. Pada variabel BI ini penerimaan ditandai dengan adanya kecenderungan niat bagi pengguna untuk tetap menggunakan/mengakses sistem/teknologi tersebut. Sedangkan AU adalah variabel yang mereprepresentasikan realitas penggunaan oleh pengguna terhadap sistem atau teknologi dimaksud. Penggunaan sistem ini ditandai dengan tingkat intensitas dan frekuensi penggunaan, serta durasi waktu yang diperlukan untuk menggunakan sistem tersebut.

Beberapa penelitian telah menggunakan Model TAM untuk melakukan studi terhadap penerimaan pengguna terhadap penerapan sistem atau teknologi tertentu. Model TAM dipergunakan untuk menganalisa penerimaan teknologi terhadap sistem informasi kepegawaian berbasis web di Kabupaten Cilacap (Mediaswati dan Sidik, 2017). Penelitian tersebut menggunakan TAM sebagai pendekatan kuantitatif disamping pendekatan kualitatif. Analisis penerimaan pengguna menggunakan Model TAM juga dilakukan untuk menganalisis penerimaan terhadap unit layanan sistem informasi di PT. KAI (Yuliana, Sanjaya, dan Shobary, 2016). Selain itu, beberapa penerapan Model TAM antara lain untuk menganalisis penerimaan pengguna terhadap implementasi sistem informasi pada e-library (Anzaeni dan Latifah, 2017), sistem penganggaran nasional (Putra, 2016), sistem keuangan syariah (Wahyuni, 2016), sistem telehealth (Tsai, 2014), serta sistem informasi asrama (Jannah, Masrur, dan Asiyah, 2015).

Sedangkan penerapan Model TAM pada sistem elektronik online telah diterapkan pada internet banking (Kazi dan Mannan, 2013 serta Danurdoro dan Wulandari, 2016). Adapun untuk penerapannya sebagai model penerimaan, diterapkan pada pengembangan teknologi pada pembangunan layanan USO - Desa Pinter (Siahaan, 2011), etextbook (Ngafesoon dan Sun, 2015), pembelajaran berbasis multimedia (Saade, Nebebe, dan Tan, 2007), serta penggunaan komputer oleh UMKM di Yogyakarta (Aisyah, Nugroho, dan Sagoro, 2014). Berdasarkan banyaknya penelitian yang menggunakan Model TAM tersebut, dapat disimpulkan bahwa Model TAM merupakan model yang memiliki tingkat reliabilitas yang cukup baik untuk dapat diterapkan pada penerimaan pengguna di bidang yang cukup luas.

Penelitian ini dilakukan dengan metode survey menggunakan kuesioner untuk melakukan studi terhadap hipotesis. Kuesioner berbentuk pernyataan dengan pilihan jawaban yang dinyatakan dengan skala Likert. Skala Likert adalah teknik pemberian skor untuk menilai sikap, pendapat, atau persepsi seseorang terhadap suatu fenomena atau keadaan (Sugiyono, 2013). Selanjutnya, untuk menjaga tingkat validitas dan reliabilitas instrumen dalam kuesioner, dilakukan pengujian validitas menggunakan Pearson Product Moment dan pengujian reliabilitas menggunakan Cronbach Alpha. Pearson Product Moment pada prinsipnya adalah melakukan uji korelasi atau hubungan antara masing-masing variabel kuesioner yang selanjutnya dibandingkan dengan nilai $r_{\text {tabel }}$ (Arikunto, 2013). Adapun Cronbach Alpha merupakan suatu rumus yang digunakan untuk mengetahui tingkat konsistensi dari item-item dalam variabel, dimana hal ini akan menunjukkan tingkat kehandalan item kuesioner yang diberikan kepada responden (Arikunto, 2013)

\section{METODE PENELITIAN}

Penelitian ini dilakukan untuk melakukan studi mengenai tingkat pengaruh suatu variabel dengan variabel lainnya menggunakan pendekatan kuantitatif. Variabel merepresentasikan faktor yang akan dikaji seberapa besar pengaruhnya terhadap perilaku pengguna yang menunjukkan penerimaan terhadap sistem atau teknologi yang diimplementasikan atau dikembangkan lebih lanjut.

Penelitian ini menggunakan model TAM yang dimodifikasi, yaitu tidak melibatkan variabel eksternal karena terfokus pada penerimaan pengguna tanpa dipengaruhi oleh pihak atau faktor yang berasal dari luar. Oleh karena itu penelitian ini hanya mempergunakan variabel PEOU, PU, BI, dan AU yang merupakan faktor internal dari pengguna itu sendiri. Adapun alur proses penelitian dapat digambarkan sesuai Gambar 2.

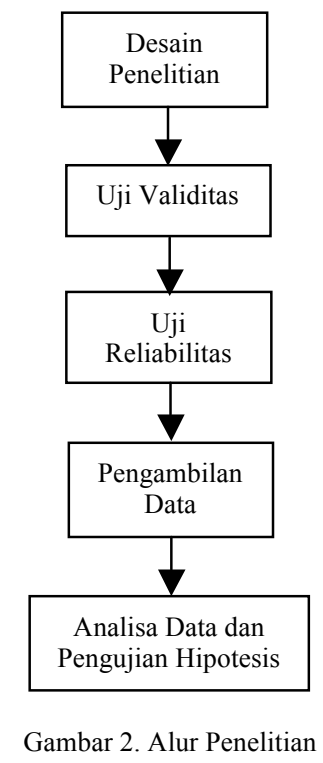

\subsection{Desain Penelitian}

Tahap ini berisi persiapan dan perancangan penelitian, yang diantaranya terdiri dari pembuatan draft kuesioner, penentuan calon responden, penentuan lokasi pengambilan data, penyiapan alat untuk analisis data, penentuan variabel dan 
hipotesis, dan persiapan pengambilan data secara langsung ke lapangan. Tahap selanjutnya adalah membuat hipothesis, dimana pada penelitian ini, ada empat hipotesis, yaitu :

H1: PEOU memiliki pengaruh positif dan signifikan terhadap PU

H2: PU memiliki pengaruh positif dan signifikan terhadap BI

H3: PEOU memiliki pengaruh positif dan signifikan terhadap BI

H4: BI memiliki pengaruh positif dan signifikan terhadap AU

Selanjutnya untuk melakukan pengambilan data, disusun sebuah kuesioner yang berisi sejumlah pernyataan dan jawaban yang akan disampaikan kepada responden untuk diisi. Pernyataan disesuaikan dengan variabel penelitian, yang dibedakan ke dalam empat variabel, yaitu PU, PEOU, BI, dan AU, dengan jumlah pernyataan adalah sebanyak 13. Pilihan jawaban yang tersedia merupakan pilihan yang disesuaikan dengan tingkat kecocokan/persetujuan menurut persepsi masingmasing responden, dimana untuk masing-masing pernyataan disediakan pilihan sebanyak lima jawaban: STS (Sangat Tidak Setuju), TS (Tidak Setuju), R (Ragu-ragu), S (Setuju), dan SS (Sangat Setuju). Masing-masing pilihan jawaban pernyataan mewakili nilai 1 sampai dengan 5 dalam skala Likert. Adapun detail pernyataan yang disampaikan kepada responden adalah seperti terdapat dalam Tabel 1.

Tabel 1. Daftar Pernyataan

\begin{tabular}{ll}
\hline Kode & Inti Pernyataan \\
\hline PEOU1 & Mudah dimengerti \\
PEOU2 & Adaptabilitas \\
PEOU3 & Usabilitas \\
PEOU4 & Fleksibilitas \\
PU1 & Efisiensi \\
PU2 & Efektivitas \\
PU3 & Produktifitas \\
PU4 & Beban kerja rendah \\
BI1 & Saat ini telah mengakses \\
BI2 & Nanti akan mengakses \\
BI3 & Merekomendasikan \\
AU1 & Frekuensi akses \\
AU2 & Durasi akses \\
\hline
\end{tabular}

\subsection{Pengujian Validitas dan Reliabilitas}

Uji validitas dan reliabilitas dilakukan untuk menguji instrumen (pengujian kuesioner). Pengujian ini dilakukan dengan pengetesan awal (pilot testing) yang dilakukan dengan pengisian kuesioner oleh sejumlah kecil responden sebanyak 30 orang agar cukup representatif (Cooper dan Schindler, 2003). Kemudian uji validitas dilakukan dengan dua tahap, yaitu melakukan penghitungan $r_{\text {hitung, dan }}$ selanjutnya membandingkan besarnya nilai $r_{\text {hitung }}$ dengan $r_{\text {tabel. }}$. Penghitungan $r_{\text {hitung dilakukan }}$ menggunakan Pearson Product Moment yang dirumuskan ada Persamaan 1 (Ghozali, 2008).

$$
r_{x y}=\frac{n \sum X Y-\left(\sum X\right)\left(\sum Y\right)}{\sqrt{\left\{n \sum X^{2}-\left(\sum X\right)^{2}\right\}\left\{n \sum Y^{2}-\left(\sum Y\right)^{2}\right\}}}
$$

Selanjutnya, $r_{\text {hitung }}$ dibandingkan dengan $r_{\text {tabel }}$ sebagai nilai referensi untuk diketahui nilai manakah diantara keduanya yang lebih besar. Apabila nilai $r_{\text {hitung }}$ lebih besar jika dibandingkan dengan $r_{\text {tabel }}$, maka instrumen (kuesioner) dinyatakan valid (Ghozali, 2008).

Uji reliabilitas dilakukan dengan Cronbach Alpha, dimana dihitung besarnya nilai $r_{\text {alpha }}(r$ hasil penghitungan dengan Cronbach Alpha) yang nanti akan dibandingkan dengan $r_{\text {tabel }}$. Kuesioner akan dinyatakan reliable apabila $r_{\text {alpha }}$ bernilai positif dan nilainya lebih besar daripada $r$ tabel (Ghozali, 2008).

\subsection{Pengumpulan Data}

Apabila hasil pengujian instrumen (kuesioner) dinyatakan valid dan reliabel, maka proses pengambilan data dapat dilanjutkan kepada populasi yang lebih luas, dengan jumlah responden yang lauh lebih banyak. Proses pengambilan data dilakukan dengan pengisian kuesioner oleh seluruh karyawan dalam divisi pemasaran, penjualan dan administrasi penjualan, support and service, dan helpdesk. Pembagian kuesioner diberikan dengan cara purposive sampling, dimana karyawan yang akan mendapat kuesioner sudah terdapat dalam daftar calon pengisi kuesioner.

Untuk meningkatkan akurasi dalam pengisian kuesioner, responden di masing-masing divisi dikumpulkan terlebih dahulu untuk mendapatkan petunjuk cara melakukan pengisian kuesioner. Selanjutnya, responden dilakukan pendampingan dalam pengisian kuesioner agar responden dapat langsung mendapatkan penjelasan secara tepat apabila terdapat hal yang ingin ditanyakannya.

\subsection{Analisis Data dan Pengujian Hipotesis}

Setelah data terkumpul, dilakukan pengolahan dan analisa data serta pengujian hipotesis menggunakan bantuan perangkat lunak. Analisa data dilakukan dengan perhitungan varians dan standar deviasi. Varians merupakan metode untuk mengetahui tingkat persebaran data terhadap ratarata yang diperoleh. Sedangkan standar deviasi dihitung untuk mengetahui sebaran data yang diperoleh dari responden. Adapun varians dan standar deviasi dapat dihitung dengan Persamaan 2 dan Persamaan 3 berikut (Sugiyono, 2013). 


$$
s^{2}=\frac{\sum\left(X_{i}-\bar{X}\right)^{2}}{n-1}
$$

$$
s=\sqrt{\frac{\sum\left(X_{i}-\bar{X}\right)^{2}}{(n-1)}}
$$

Pengujian hipotesis pada dasarnya adalah melakukan uji t, yaitu untuk mengetahui sejauhmana nilai pengaruh suatu variabel dengan variabel lainnya yang ditunjukkan dengan suatu nilai koefisien. Hal ini dilakukan dengan melakukan perhitungan dengan rumus $t_{\text {hitung }}$ dan kemudian dibandingkan dengan nilai $t_{\text {tabel }}$ (Arikunto, 2013). Apabila nilai $t_{\text {hitung }}$ lebih besar dari nilai $t$, maka hipotesis diterima. Adapun rumus untuk menghitung nilai $t_{\text {hitung }}$ ditampilkan pada Persamaan 4 berikut (Arikunto, 2013).

$$
t_{\text {hitung }}=\frac{r_{x y} \sqrt{(n-2)}}{\sqrt{\left(1-r_{x y}^{2}\right)}}
$$

\section{HASIL DAN PEMBAHASAN}

\subsection{Uji Validitas dan Reliabilitas}

Berdasarkan pengujian validitas diperoleh nilai $r_{\text {hitung }}$ sebesar 0,183, sedangkan $r_{\text {tabel }}$ adalah 0,1401 . Untuk uji reliabilitas, diperoleh $r_{\text {alpha }}$ sebesar 0,37 . Dari hasil perhitungan tersebut dapat diketahui bahwa $r_{\text {hitung }}$ lebih besar dari $r_{\text {tabel }}$ dan $r_{\text {alpha }}$ lebih besar dari $r_{\text {tabel. }}$ Berdasarkan pengujian ini dapat dikatakan bahwa instrument kuesioner dinyatakan valid dan sangat reliabel untuk dilanjutkan ke tahap pengambilan data.

\begin{tabular}{ccc}
\multicolumn{2}{c}{ Tabel 2. Nilai $r$} \\
\hline Jenis r & Nilai & Kondisi (Nilai $\mathbf{r}_{\text {tabel }}=\mathbf{0 , 1 4 0 1 )}$ \\
\hline $\mathrm{r}_{\text {hitung }}$ & 0,183 & $\mathrm{r}_{\text {hitung }}>\mathrm{r}_{\text {tabel }}$ \\
\hline $\mathrm{r}_{\text {alpha }}$ & 0,37 & $\mathrm{r}_{\text {alpha }}>\mathrm{r}_{\text {tabel }}$ \\
\hline
\end{tabular}

\subsection{Profil Responden}

Responden yang mengisi kuesioner merupakan karyawan yang berasal dari lima divisi, yaitu pemasaran, sales and administration, support and service, serta Helpdesk dengan jumlah responden adalah 141. Adapun profil responden secara detail seperti terlihat pada Tabel 3 berikut.

Tabel 3. Profil Karyawan yang Menjadi Responden

\begin{tabular}{lcc}
\hline Parameter & Jumlah & Persentase \\
\hline Jenis kelamin & & \\
Pria & 86 & $61 \%$ \\
Wanita & 55 & $39 \%$ \\
\hline Tingkat pendidikan & & \\
SMA / SMK & 14 & $10 \%$
\end{tabular}

\begin{tabular}{lcr} 
Diploma & 26 & $18,4 \%$ \\
Sarjana Strata 1 (S1) & 81 & $57,4 \%$ \\
Magister (S2) & 20 & $14,2 \%$ \\
Doktor (S3) & 0 & $0 \%$ \\
\hline Divisi & & \\
Pemasaran & 25 & $18 \%$ \\
Penjualan & 62 & $44 \%$ \\
Support \& Services & 37 & $26 \%$ \\
Helpdesk & 17 & $12 \%$ \\
\hline
\end{tabular}

\subsection{Pengujian Hipotesis}

Berdasarkan pengujian hipotesis, diperoleh hasil sebagai berikut :

H1 : pengaruh PEOU terhadap PU diperoleh sebesar 0,43 dengan nilai signifikansi 0,031.

$\mathrm{H} 2$ : pengaruh PU terhadap BI diperoleh sebesar 0,67 dengan nilai signifikansi 0,02 .

H3 : pengaruh PEOU terhadap BI diperoleh sebesar 0,58 dengan nilai signifikansi 0,014.

H4 : pengaruh BI terhadap AU diperoleh sebesar 0,77 dengan nilai signifikansi 0,042 .

Tabel 4. Hasil Uji Hipotesis

\begin{tabular}{cccc}
\hline Hipotesis & $\begin{array}{c}\text { Variabel Pengaruh }- \\
\text { Terpengaruh }\end{array}$ & $\begin{array}{c}\text { Nilai } \\
\text { Pengaruh }\end{array}$ & $\begin{array}{c}\text { Nilai } \\
\text { Signifikansi }\end{array}$ \\
\hline H1 & PEOU terhadap PU & 0,43 & 0,031 \\
\hline H2 & PU terhadap BI & 0,67 & 0,02 \\
\hline H3 & PEOU terhadap BI & 0,58 & 0,014 \\
\hline H4 & BI terhadap AU & 0,77 & 0,042 \\
\hline
\end{tabular}

Tabel 4 menunjukkan hasil pengujian hipotesis untuk masing-masing variabel dan pengaruhnya terhadap variabel lainnya. Untuk pengujian masingmasing hipotesis, diperoleh bahwa nilai pengaruh (koefisien) menunjukkan nilai positif pada keempat hipotesis, dan nilai signifikansi yang diperoleh besarnya kurang dari 0,05 pada keempat hipotesis. Hal ini menunjukkan bahwa keempat hipotesis tersebut dapat diterima.

Adapun penjelasan masing-masing hipotesis dapat dijelaskan sebagai berikut. Indikator kemudahan penggunaan yang dirasakan oleh responden adalah sistem mudah dimengerti, kemudahan penyesuaian diri dengan sistem, kemudahan penggunaan, dan flexibilitas akses. Persepsi kemudahan penggunaan akan membuat pengguna dapat merasakan manfaat dari penggunaan sistem CRM yang dioperasikan, dimana hal ini ditunjukkan dengan nilai pengaruh sebesar 0,43 yang berarti memiliki pengaruh yang positif dan signifikan.

Manfaat yang memberikan pengaruh positif bagi penggunanya ditandai dengan adanya efisiensi waktu dan biaya dalam bekerja, efektivitas penyelesaian pekerjaan, peningkatan produktivitas kerja, dan beban kerja yang menjadi berkurang. Manfaat yang dirasakan pengguna ini akan membuat pengguna memiliki persepsi positif terhadap sistem dimana dibuktikan dengan nilai pengaruh yang 
positif dan signifikan yaitu sebesar 0,67 . Hal ini membuat pengguna bersedia terus menggunakan sistem secara konsisten dalam melaksanakan pekerjaan hariannya. Hal ini juga terjadi ketika pengguna merasakan manfaat terhadap penggunaan sistem, yang ditunjukkan dengan nilai pengaruh sebesar 0,58 yang juga berarti memiliki pengaruh yang positif dan signifikan.

Perilaku penggunaan sistem oleh pengguna berpengaruh positif terhadap penggunaan secara nyata, dimana ketika pengguna menggunakan sistem dalam melakukan pekerjaannya, maka pengguna akan semakin sering menggunakan sistem, bahkan dengan durasi waktu yang lebih lama dari biasanya. Nilai pengaruh dari variabel perilaku penggunaan sistem terhadap penggunaan secara nyata dibuktikan dengan nilai pengaruh yang positif dan signifikan, yaitu sebesar 0,77 .

\section{KESIMPULAN}

Serangkaian proses dalam penelitian ini dimaksudkan untuk melakukan kajian terhadap faktor-faktor yang berpengaruh dalam penerimaan pengguna CRM di sebuah perusahaan penyedia layanan SI/TI. Berdasarkan studi, diperoleh bahwa penerimaan pengguna dipengaruhi oleh faktor manfaat penggunaan yang dirasakan oleh pengguna, kemudahan penggunaan sistem, serta perilaku pengguna dalam mengoperasionalkan sistem. Kesemua faktor tersebut memiliki pengaruh positif yang signifikan, dimana semakin tinggi manfaat, kemudahan, serta penggunaan sistem, maka tingkat penerimaan pengguna juga akan semakin tinggi, yang dibuktikan dengan durasi waktu dan frekuensi penggunaan sistem yang semakin tinggi. Sehingga, berdasarkan kajian menggunakan Model TAM, tingkat penerimaan pengguna terhadap sistem CRM adalah positif dan signifikan.

\section{DAFTAR PUSTAKA}

AISYAH, M. N., NUGROHO, M. A. \& SAGORO, E. M. 2014. Pengaruh Technology Readiness terhadap Penerimaan Teknologi Komputer pada UMKM di Yogyakarta. Jurnal Economia, 10 (2), 105-119.

ANZAENI, M. W. DAN LATIFAH, L. 2017. Analisis Penerimaan Penggunaan Otomasi Perpustakaan UNNES Berdasarkan Pendekatan Technology Acceptance Model (TAM). Economic Education Analysis Journal, 6 (2), 530-548.

ARIKUNTO, S. 2013. Prosedur Penelitian: Suatu Pendekatan Praktik. Jakarta: Rineka Cipta.

AZHARY, R. dan SARI, H. Z. I. 2008. Modelmodel User Acceptence. Fakultas Komputer Universitas Indonesia, Depok.
COOPER, D. R. dan SCHINDLER, P. S. 2003. Business Research Methods. 8th ed. Boston : Mc Graw Hill.

DANURDORO, K. dan WULANDARI, D. 2016. The Impact of Perceived Usefulness, Perceived Ease of Use, Subjective Norm, and Experience Toward Student's Intention to Use Internet Banking. Jurnal Ekonomi dan Studi Pembangunan, 8 (1), 17-22.

DAVIS, F. D. 1989. Perceived Usefulness, Perceived Ease of Use, and User Acceptance of Information Technology. MIS Quaterly, 13 (3), 319-339.

FATMAWATI, E. 2015. Technology Acceptance Model (TAM) untuk Menganalisis Penerimaan terhadap Sistem Informasi Perpustakaan. Jurnal Iqra', 9 (1), 1-13.

GHOZALI, I. 2008. Generalized Structured Component Analysis (GSCA): Model Persamaan Struktural Berbasis Komponen. Semarang: Badan Penerbit Universitas Diponegoro.

HAKIM, M. M. 2017a. IT Audit of IT Service Provider Using COBIT 4.1 Framework: Case Study at PT. XYZ. Fountain of Informatics Journal, 2 (2), 28-32.

HAKIM, M. M. 2017b. Information System Strategic Planning in IS / IT Service Provider. Jurnal Ilmiah Penelitian dan Pembelajaran Informatika (JIPI), 2 (2), 118-127.

JANNAH, E. N., MASRUR, M. \& AISYAH, S. 2015. Penerapan Framework Yii dalam Pembangunan Sistem Informasi Asrama Santri Pondok Pesantren sebagai Media Pencarian Asrama Berbasis Web. Journal of Information System Engineering and Business Intelligence, 1 (2), 49-58.

KAZI, A. K. dan MANNAN, M. A. 2013. An Empirical Study of Factors Influencing Adoption of Internet Banking among Students of Higher Education: Evidence from Pakistan. International Journal of Finance \& Banking Studies, 2 (2), 87-99.

MEDIASWATI, R. dan SIDIK, F. 2013. Analisa Penerapan Aplikasi Pelaporan Kepegawaian Berbasis Web pada Badan Kepegawaian Daerah Kabupaten Cilacap. Jurnal Kebijakan dan Administrasi Publik, 17 (1), 4-14.

NGAFEESON, M. N. dan SUN, J. 2015. The Effects of Technology Innovativeness and System Exposure on Student Acceptance of E-Textbooks. Journal of Information Technology Education: Research, 14 (-), 55-71. 
PUTRA, D. M. 2016. The Influence on Factors In Attitude Toward Acceptance of The Information System Using Technology Acceptance Model (TAM) Case Study SPAN System in Indonesia. International Journal of Scientific and Technology Research, 5 (5), 231-236.

SAADE, R. G., NEBEBE, F. \& TAN, W. 2007. Viability of The "Technology Acceptance Model" in Multimedia learning Environments: A Comparative Study. Interdisciplinary Journal of e-Skills and Lifelong Learning, 3 (-), 175-184.

SIAHAAN, L. J. 2011. Penelitian Perilaku Pengguna Internet pada Desa Pinter Hasil Pembangunan USO dengan Pendekatan Technology Acceptance Model (TAM) di Provinsi Jawa Tengah. Buletin Pos dan Telekomunikasi: Media Komunikasi Ilmiah, 9 (1), 71-92.

SUGIYONO. 2013. Metode Penelitian Kuantitatif, Kualitatif, dan R \& D. Bandung: Alfabeta.

TSAI, C. H. 2014. Integrating Social Capital Theory, Social Cognitive Theory, and The Technology Acceptance Model to Explore a Behavioral Model of Telehealth Systems. International Journal of Environmental Research and Public Health, 11 (5), 49054925.

VENKATESH, V. dan DAVIS, F. D. 1996. A Model of The Antecedents of Perceived Ease of Use: Development and Test. Decision Sciences. 27 (3), 451-481.

WAHYUNI, T. 2016. The Influence of Technology Acceptance Model (TAM) on The Users' Behavior of Sikesya Application in IAIN Surakarta. Shirkah Journal of Economics and Business, 1 (1), 47-72.

YULIANA, Y., SANJAYA, R., \& SHOBARY, M. N. 2016. Analisis Kepuasan Pegawai terhadap Layanan Unit Sistem Informasi Menggunakan Technology Acceptance Model di PT. Kereta Api Indonesia (Persero). Jurnal Informatika, 3 (2), 290298. 